\title{
Pemetaan Sektor Agribisnis Pangan Unggulan di Kabupaten Musi Rawas
}

\section{Mapping of the Leading Food Agribusiness Sector in Musi Rawas Regency}

\section{Zaini Amin ${ }^{1 *}$, Andry ${ }^{1}$, Edy Humaidi ${ }^{2}$}

${ }^{1}$ Program Studi Agribisnis Fakultas Pertanian Universitas Musi Rawas

${ }^{2}$ Program Studi Agribisnis Jurusan Ekonomi dan Bisnis Politeknik Negeri Lampung

*E-mail: zaini_amin@ymail.com)

\begin{abstract}
This study aims to map food commodities that are feasible to develop in Musi Rawas Regency. The method of calculation used to determine superior and non-superior commodities is the Location Quotient (LQ) method. The data used includes secondary data obtained from the Central Statistics Agency and the Department of Agriculture and Animal Husbandry of Musi Rawas Regency in 2019, as well as primary data from interviews with farmers. The results showed that of the eight food commodities, there were 6 which were superior commodities, namely lading rice, sweet potato, maize, peanuts, green beans, and soybeans, while the other two, namely lowland rice and cassava, were non-superior food commodities.
\end{abstract}

Keywords: mapping, agribusiness sector, superior food.

Disubmit: 29 Januari 2021; Diterima: 20 Februari 2021; Disetujui: 14 April 2021

\section{PENDAHULUAN}

Sektor pertanian dinilai mampu bertahan dari krisis ekonomi ketika sektor lain mengalami keterpurukan. Sektor pertanian merupakan sektor utama yang strategis dimana menjadi kekuatan dasar perekonomian masyarakat pedesaan dimana sebagian besar masyarakat menggantungkan hidupnya, dan menjadi ketahanan masyarakat ketika Indonesia mengalami krisis (Arifin, 2004). Subsektor tanaman pangan memiliki arti strategis dalam perekonomian nasional dan daerah, karena sektor ini menyediakan bahan paling esensial untuk kebutuhan hidup manusia.

Pertumbuhan suatu daerah pada dasarnya dipengaruhi oleh keunggulan komparatif dan kompetitif (Haryono \& Kasymir,2011.; Wicaksono, 2011). Secara empiris, beberapa hasil penelitian menunjukkan bahwa hasil analisis LQ dan klasifikasi tipologi menunjukkan bahwa setiap daerah memiliki sektor unggulan yang berbeda (Adhitama R, 2012; Setiawan D., 2006). Secara logika, cukup beralasan jika studi sebelumnya menyatakan bahwa pengembangan agribisnis tanaman pangan perlu mempertimbangkan potensi sumberdaya lahan dan agroekosistem melalui pendekatan komoditi unggulan wilayah (Kairupan, 2013), oleh karena itu penentuan komoditas pertanian unggulan khususnya tanaman pangan merupakan langkah awal bagi daerah untuk menciptakan pertumbuhan ekonomi daerah.

Musi Rawas merupakan salah satu Kabupaten di Provinsi Sumatera Selatan yang memiliki Produk Domestik Bruto (PDRB) sebesar Rp17.499.935,80. Kontribusi tertinggi datang dari sektor pertanian yaitu 31,55 persen (Badan Pusat Statistik, 2019). Kabupaten Musi Rawas merupakan salah satu penghasil komoditas pangan di Sumatera Selatan, sehingga dapat dikatakan bahwa Kabupaten ini merupakan sentra 
produksi pangan di Provinsi Sumatera Selatan, akan tetapi belum dipetakan tanaman pangan yang menjadi unggulan berdasarkan studi empiris. Oleh karena itu, penelitian ini bertujuan untuk memetakan komoditas tanaman pangan unggulan yang layak dikembangkan di Kabupaten Musi Rawas, sehingga diharapkan dapat menghasilkan komoditas yang memiliki keunggulan komparatif yang dapat berkembang menjadi produk yang memiliki keunggulan kompetitif.

\section{METODE PENELITIAN}

Lokasi penelitian ini di Kabupaten Musi Rawas. Penetapan lokasi ini ditentukan secara purposive (sengaja) dengan pertimbangan sebagai berikut: 1) kontribusi sektor pertanian dalam PDRB Kabupaten Musi Rawas menunjukkan persentase tertinggi; dan 2) Musi Rawas merupakan salah satu daerah utama penghasil pangan di Provinsi Sumatera Selatan (Badan Pusat Statistik., 2019).

Sumber data yang digunakan adalah data primer dan data sekunder. Data primer yang digunakan dalam penelitian ini meliputi data hasil wawancara dengan kelompok tani yang bercocok tanam tanaman pangan dan pedagang pengumpul tanaman pangan, guna mendukung pengambilan data sekunder. Data sekunder yang digunakan adalah data dari Kabupaten Musi Rawas tahun 2019 yang diperoleh dari Badan Pusat Statistik Musi Rawas.

Penentuan komoditas pangan unggulan di Kabupaten Musi Rawas diperoleh dengan melihat dokumen produksi tanaman pangan yang diproduksi di setiap kecamatan, kemudian dianalisis menggunakan metode Location Quotient (LQ) dengan alat analisis Ms. Excel 2018. Location Quotient Analysis (LQ) merupakan salah satu pendekatan tidak langsung yang digunakan untuk menentukan apakah suatu sektor pertanian merupakan sektor unggulan atau non unggulan (Bachrein S, 2003; Lumbantoruan, D. M., B. Sartono, 2015). Nilai LQ memberikan gambaran suatu daerah dalam menghasilkan komoditas sebagai komoditas basis. Komoditas tanaman pangan yang dianalisis adalah padi sawah, padi ladang, ketela pohon, ketela rambat, jagung, kacang tanah, kacang hijau, dan kedelai. Secara matematis model analisis LQ dapat dilihat pada persamaan berikut.

$\mathrm{LQ}=\frac{E_{i j} / E_{j}}{E_{i n} / E_{n}}$

\section{Dimana:}

$\mathrm{E}_{\mathrm{ij}} \quad=$ Jumlah produksi komoditas i di Kecamatan

$\mathrm{E}_{\mathrm{j}} \quad=$ Total produksi subsektor pertanian di Kecamatan

$\mathrm{E}_{\text {in }} \quad=$ Jumlah produksi komoditas i di Kabupaten Musi Rawas

$\mathrm{E}_{\mathrm{n}} \quad=$ Total produksi subsektor pertanian di Kabupaten Musi Rawas

Apabila nilai LQ dihitung maka akan diperoleh sebagai berikut :

1. Jika nilai LQ suatu komoditas > 1, maka komoditas tersebut dapat dikatakan sebagai komoditas basis.

2. Jika nilai LQ suatu komoditas $<1$, maka komoditas tersebut dapat dikatakan sebagai komoditas non basis.

3. Jika nilai LQ suatu komoditas $=1$, maka komoditas tersebut dapat dikatakan komoditas yang hanya dapat memenuhi kebutuahan daerahnya sendiri.

\section{HASIL DAN PEMBAHASAN}

Keunggulan komparatif merupakan keunggulan suatu komoditas yang didukung oleh sumber daya alam yang ada, dimana di daerah lain tidak mampu memproduksinya atau komoditas yang memiliki dukungan bahan baku dalam proses produksi yang tersedia pada lokasi tersebut (Hardison, 2003). Hasil 
Amin, Andry, Humaidi : Pemetaan Sektor Agribisnis Pangan Unggulan di Kabupaten Musi Rawas..........

analisis LQ menunjukkan kemampuan suatu wilayah dalam menghasilkan komoditas unggulan (Abidin, 2018; Hendayana, 2003). Hasil analisis LQ dalam penelitian ini dapat dilihat pada Tabel 1 berikut.

Tabel 1. Hasil Analisis LQ Komoditi Pangan di Kabupaten Musi Rawas

\begin{tabular}{lcc}
\hline \multicolumn{1}{c}{ Tanaman Pangan } & Nilai LQ & Keterangan \\
\hline Padi Sawah & 0,73 & Non Unggulan \\
Padi Ladang & 2,17 & Unggulan \\
Ketela Pohon & 0,97 & Non Unggulan \\
Ketela Rambat & 1,30 & Unggulan \\
Jagung & 1,79 & Unggulan \\
Kacang Tanah & 1,35 & Unggulan \\
Kacang Hijau & 2,70 & Unggulan \\
Kacang Kedelai & 2,26 & Unggulan \\
\hline
\end{tabular}

Sumber: Data Primer Diolah, 2019

Tabel 1 menunjukkan bahwa hanya enam dari delapan komoditas yang menunjukkan LQ> 1 . Komoditi yang dimaksud adalah padi ladang, ketela rambat, jagung, kacang tanah, kacang hijau, dan kedelai, sedangkan dua sisanya yaitu padi sawah dan ketela pohon memiliki nilai $L Q<1$. Hal ini berarti hanya enam komoditas pangan yang menjadi unggulan di Kabupaten Musi Rawas. Kondisi ini menjadi menarik untuk dibahas dimana terdapat dua komoditi non unggulan yaitu padi sawah dan ketela pohon. Dikatakan demikian, karena: pertama, daerah ini merupakan sentra produksi beras di Provinsi Sumatera Selatan, dan beras merupakan bahan pangan pokok. Artinya komoditas beras memiliki posisi strategis, baik di Kabupaten Musi Rawas maupun di Provinsi Sumatera Selatan (Badan Pusat Statistik., 2019), namun totalitas komoditas tersebut bukan merupakan komoditas pokok; Kedua, ketela pohon merupakan komoditas pangan kedua setelah beras. Kajian terhadap perilaku konsumen terhadap beras menunjukkan bahwa kenaikan harga beras menyebabkan pendapatan riil masyarakat menurun, dan secara signifikan meningkatkan konsumsi karbohidrat non beras, khususnya ketela pohon. Hal ini berarti ketela pohon merupakan produk substitusi beras (Amin, 2016; Mufidah, 2006; Suyastiri, 2008). Selanjutnya untuk mendalami studi pemetaan agribisnis tanaman pangan daerah, analisis akan dirinci menurut wilayah kecamatan. Hasil analisis LQ untuk delapan komoditas di 14 kabupaten disajikan pada Tabel 2.

Table 2. Hasil Analisis LQ Komoditi Pangan Setiap Kecamatan di Kabupaten Musi Rawas

\begin{tabular}{lcccccccc}
\hline \multirow{2}{*}{ Kecamatan } & \multicolumn{7}{c}{ Nilai LQ } \\
\cline { 2 - 9 } & $\begin{array}{c}\text { Padi } \\
\text { Sawah }\end{array}$ & $\begin{array}{c}\text { Padi } \\
\text { ladang }\end{array}$ & $\begin{array}{c}\text { Ketela } \\
\text { Pohon }\end{array}$ & $\begin{array}{c}\text { Ketela } \\
\text { Rambat }\end{array}$ & Jagung & $\begin{array}{c}\text { Kacang } \\
\text { Tanah }\end{array}$ & $\begin{array}{c}\text { Kacang } \\
\text { hijau }\end{array}$ & $\begin{array}{c}\text { Kacang } \\
\text { Kedelai }\end{array}$ \\
\hline STL Ulu & 1.24 & 0.53 & .21 & 1.68 & 0.63 & 1.30 & 1.46 & 0.45 \\
Terawas & & & & & & & & \\
Selangit & 0.27 & 7.47 & 0.23 & - & 1.03 & 0.57 & 2.73 & 2.78 \\
Sumber Harta & 1.35 & .17 & .19 & 0.65 & .20 & 0.55 & 0.52 & .17 \\
Tugumulyo & 1.33 & - & 0.51 & 0.49 & .17 & .91 & .73 & .20 \\
Purwodadi & 1.19 & - & 0.63 & 2.75 & .89 & 3.14 & 3.89 & 1.24 \\
\hline
\end{tabular}


Jurnal Penelitian Pertanian Terapan

\begin{tabular}{lcccccccc}
\hline Muara Beliti & 1.34 & 0.30 & 0.02 & - & .37 & 0.32 & .13 & 0.14 \\
TP. Kepungut & - & 2.60 & 0.47 & 4.00 & 7.25 & .81 & 6.72 & 1.47 \\
Jayaloka & 0.08 & 5.01 & 0.68 & 1.84 & 3.54 & 3.08 & - & 9.74 \\
Sukakarya & 0.56 & 2.79 & 1.42 & 1.86 & 1.69 & 2.33 & 6.48 & 4.75 \\
Muara & 0.38 & 2.19 & 0.72 & 1.62 & 4.53 & 0.64 & .19 & 2.62 \\
Kelingi & & & & & & & & \\
BTS Ulu & 0.40 & 3.91 & 2.14 & - & 1.10 & - & - & 4.57 \\
Tuah Negeri & 0.68 & 3.15 & 0.30 & 2.38 & 2.00 & 4.57 & 0.45 & 2.14 \\
Muara & 0.14 & 2.00 & 5.70 & 0.22 & 1.09 & 0.28 & 0.33 & - \\
Lakitan & & & & & & & & \\
Megang Sakti & 1.28 & 0.26 & 0.32 & 0.71 & 0.54 & 0.43 & .22 & 1.35 \\
\hline
\end{tabular}

Sumber: Data Primer Diolah, 2019

Tabel 2 menunjukkan bahwa komoditas unggulan padi sawah (LQ> 1) berada di Kecamatan Suku Tengah Lakitan (STL) Ulu Terawas, Sumber Harta, Purwodadi, Muara Beliti, dan Kecamatan Megang Sakti; Komoditi padi ladang berada di Kecamatan Selangit, Kecamatan Tiang Pumpung (TP) Kepungut, Jayaloka, Suka Karya, Muara Kelingi, Bulang Tengah Suku (BTS) Ulu, Tuah Negeri, dan Kecamatan Muara Lakitan/ Komoditi unggulan ketela pohon, berada di Kecamatan Sukakarya, Kecamatan Ulu BTS, dan Kecamatan Muara Lakit; Komoditas berunggulan ubi jalar terdapat di Kelurahan STL Ulu Terawas, Purwodadi, TP. Kabupaten Kepungut, Jayaloka, Sukakarya, Muara Kelingi, dan Tuah Negeri.

Komoditas unggulan jagung berada di Kecamatan Selangit, TP. Kepungut, Jayaloka, Sukakarya, Muara Kelingi, BTS Ulu, Tua Negeri dan Distrik Muara Lakitan. Komoditas unggulan kacang tanah berada di Kecamatan STL Ulu Terawas, Purwodadi, Jayaloka, Sukakarya, dan Tua Negeri. Komoditas unggulan kacang hijau di STL Ulu Terawas Kecamatan Selangit Purwodadi TP Kepungut dan Sukakarya. Komoditas unggulan kedelai berada di Kecamatan Selangit, Purwodadi, TP Kepungut, Jayaloka, Sukakarya, Muara Kelingi, BTS Ulu, Tuah Negeri dan Megang Sakti.

Kondisi di atas menunjukkan bahwa pengembangan komoditas padi dataran rendah secara berurutan sesuai nilai LQ dapat dikembangkan di Kecamatan Sumber Harta (LQ = 1,35), Kecamatan Muara Beliti (LQ = 1,34), Tugumulyo ( $\mathrm{LQ}=1,33$ ), Megang Sakti (1,28), STL Ulu Dibimbing ( $\mathrm{LQ}=1,24)$; dan Kabupaten Purwodadi (LQ = 1.19). Namun urutannya berbeda jika dilihat dari luas areal tanam padi menurut Dinas Pertanian dan Peternakan (2019) masing-masing Kecamatan Megang Sakti (13.600 ha), STL Ulu Terawas (13.517 ha), Sumber Harta (8.849 ha)), Tugumulyo (8.272), Muara Beliti (6.453 ha), dan Kabupaten Purwodadi (4.928 ha). Perbedaan ini lebih disebabkan oleh perbedaan produktivitas, selain luas lahan. Produktivitas lahan di Kecamatan Tugumulyo, Kecamatan Muara Belti, dan Megang Sakti rata-rata di atas 6 ton / ha, sedangkan rata-rata produktivitas lahan di Kecamatan STL Ulu Terawas dan Sumber Harta di bawah 6 ton per hektar. Gambaran yang lebih rinci tentang LQ tanaman pangan tiap kecamatan di Kabupaten Musi Rawas disajikan pada Gambar 1

Gambar 1, berdasarkan peta Kabupaten Musi Rawas ([BPS] Badan Pusat Statistik., 2019) menunjukkan bahwa kecamatan yang berada di dalam kotak coklat (Kecamatan Selangit, TP Kepungut, Jayaloka, Sukakarya, Muara Kelingi, BTS Ulu, Tuah Negeri, dan Kecamatan Muara Lakitan) merupakan kawasan yang didominasi oleh lahan kering. Kawasan ini rupanya memiliki beragam komoditas unggulan. Berbeda dengan kecamatan yang berada di dalam kotak hijau (STL. Ulu Terawas, Sumber Harta, 
Tugumulyo, Purwodadi, dan Muara Beliti) yang merupakan daerah yang didominasi persawahan, komoditas unggulan yang dapat dikembangkan hanya sebatas padi, kecuali STL Ulu Terawas, dan Purwodadi).

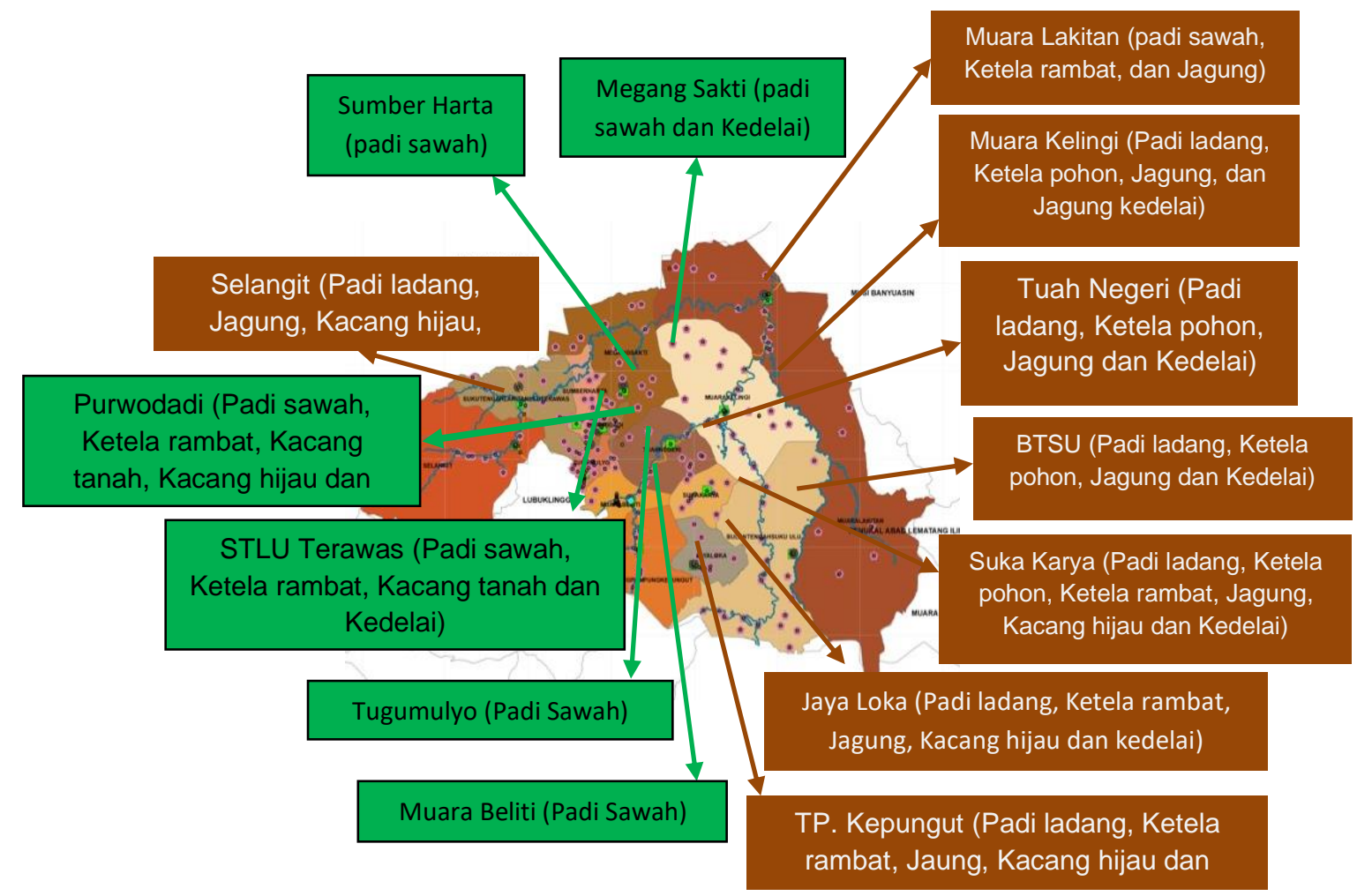

Gambar 1. Peta Pengembangan Komoditas di 14 Kecamatan di Kabupaten Musi Rawas

Berdasarkan kajian di atas, dalam rangka memenuhi kebutuhan beras di daerah, Kabupaten Musi Rawas sebagai pemasok beras Sumatera Selatan, tidak perlu serta merta mengalihkan kebijakan ke komoditas non beras, tetapi ada rekayasa kebijakan komoditas yang terintegrasi sehingga bisa dilakukan. tidak menggeser kebijakan beras atau padi sawah. Kajian Amin (2015) menunjukkan bahwa tidak terdapat perbedaan pendapatan yang signifikan antara usahatani padi monokultur dengan pola monokultur ikan, dengan pola usahatani ikan-padi, dan pola integrasi padi dan ikan. Memang, pendapatan dari usaha monokultur ikan sangat berbeda dengan usaha monokultur padi. Namun dalam usaha monokultur ikan dilihat dari mahalnya biaya produksinya, usaha ini mempunyai resiko yang tinggi, disisi lain, secara empiris (Suntoro, Mujiyo, 2013) menunjukkan bahwa upaya monokultur ikan berkontribusi terhadap pemanasan global, yang ditunjukkan dengan potensi rata-rata sebesar 3117,64 eq. CO2 / kg tanah. Lebih lanjut, berdasarkan penelitian ini, penelitian Amin (2015) merekomendasikan penerapan pola rotasi padi-sawah pada usahatani padi. Kebijakan ini diharapkan, petani padi dapat meningkatkan pendapatannya, tanpa mengesampingkan kelestarian lingkungan, dan tanpa mengubah kebijakan penyediaan beras di sawah.

Kebijakan lain yang dapat diambil dalam penyediaan pangan adalah melalui intensifikasi, ekstensifikasi, dan diversifikasi tanaman pangan di lahan kering. Pasalnya, di lahan kering perkembangan tanaman pangan di lahan kering dilihat dari nilai LQ (> 1) bisa lebih beragam. Hasil pemetaan (Gambar 1) menunjukkan bahwa di daerah dataran tinggi dapat dikembangkan 4-5 komoditi yang terdiri dari padi ladang, jagung, ketela rambat, ketela pohon, kacang hijau, dan kedelai.

Kegiatan intensifikasi dan ekstensifikasi, sudah rutin dilakukan petani, namun temuan di lapangan menunjukkan bahwa teknologi diversifikasi tanaman pangan belum diterapkan secara optimal. Untuk optimasi produksi dalam pola tanam diperlukan pemahaman tentang kondisi curah hujan setempat 
(Makaborang M, Geonadi S, 2009). Data dari (Badan Pusat Statistik, 2019) menunjukkan curah hujan di Kabupaten Musi Rawas berkisar antara $3000 \mathrm{~mm}-4000 \mathrm{~mm}$ per tahun, dengan termasuk dalam pola curah hujan IV C. Merujuk publikasi Balai Penelitian Agroklimat dan Hidrologi (2007), pola tanam yang dianjurkan adalah sawah dan palawija .

Berdasarkan referensi di atas maka pola rotasi tanaman dan integrasi tanam diatur seperti pada Gambar 2.

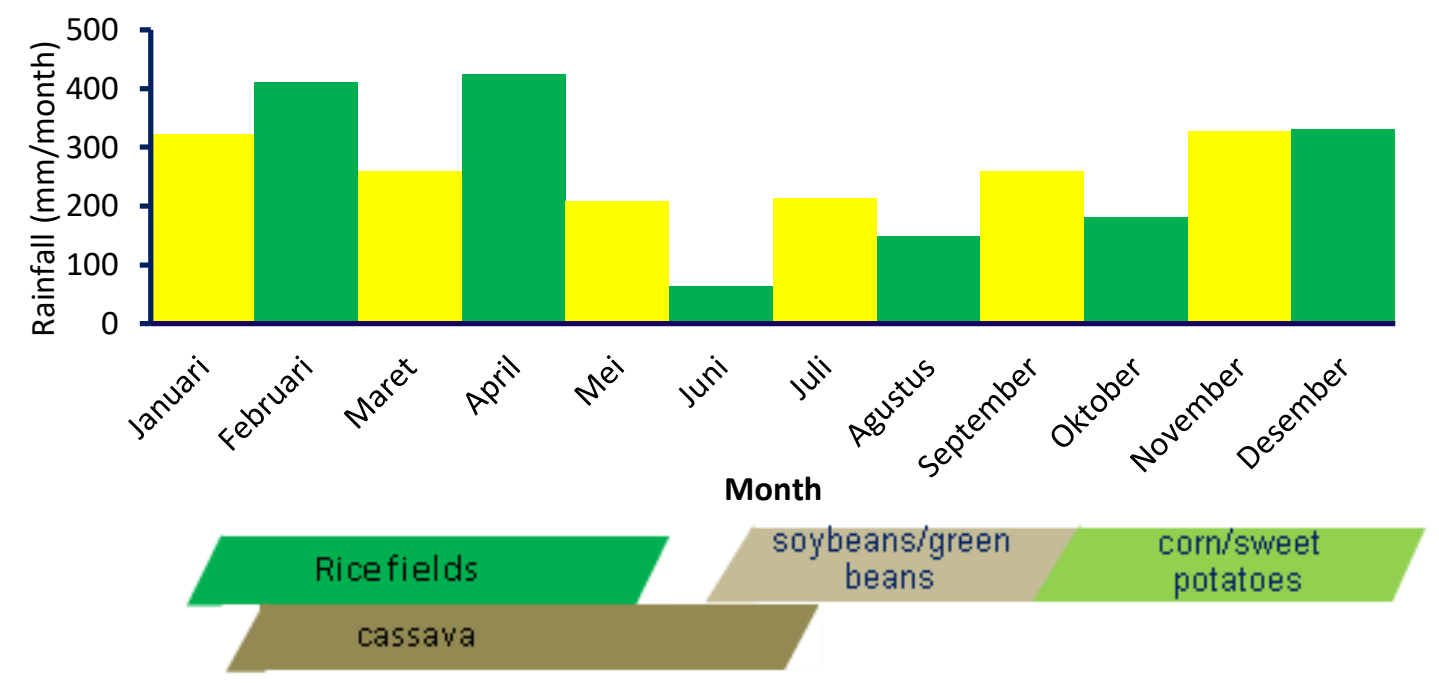

Gambar 2. Pola Tanam Lahan Kering yang disarankan oleh Balai Penelitian Agroklimat dan Hidrologi Pola Curah Hujan IVC

Gambar 2 menunjukkan bahwa pola tanam yang dapat dilakukan adalah pola rotasi padi, dengan jarak tanam, dalam baris $25 \times 25 \mathrm{~cm}$ dan antar baris $200 \mathrm{~cm}$, dan diintegrasikan dengan ketela pohon 300x40 cm, setelah bulan Juli ditanam kacang hijau atau kedelai, menurut wilayah unggulan yang tercermin dari nilai LQ, dan terakhir ditanam jagung atau ketela pohon sesuai dengan unggulan lokalnya (sesuai komoditas unggulan).

Ada dua hal yang dapat ditarik dalam penerapan pola tanam yaitu: terjadinya optimalisasi lahan karena semua bahan pokok dapat diusahakan, dan lahan yang ditumbuhi tanaman sepanjang tahun dengan tanaman yang berbeda, sehingga mengurangi biaya pengendalian gulma. dan hama dan penyakit. Penerapan pola tanam secara logis dapat meningkatkan keunggulan komparatif menjadi keunggulan kompetitif, sebagaimana Humaidi, et al, (2020); Saragih, (2001) mengemukakan bahwa salah satu arah pengembangan agribisnis adalah mengembangkan komoditas unggulan komparatif menjadi komoditas yang berdaya saing.

\section{KESIMPULAN DAN SARAN}

Hasil penelitian menunjukkan bahwa secara umum dari delapan komoditi pangan terdapat 6 yang merupakan komoditi unggulan yaitu padi ladang, ketela rambat, jagung, kacang tanah, kacang hijau, dan kacang kedelai, sedangkan dua lainnya yaitu padi sawah dan ketela pohon, merupakan komodit pangan non unggulan. Selanjutnya untuk daerah yang didominasi oleh lahan basah komoditi unggulannya adalah padi sawah, sedangkan lahan kering komoditas unggulan yang sangat beragam, terdiri dari padi ladang, ubi jalar, ketela pohon, jagung, kacang hijau, dan kedelai. Berdasarkan hasil penelitian ini, disarankan untuk menerapkan pola integrasi usahatani terutama di wilayah lahan kering.

\section{DAFTAR PUSTAKA}

[BPS] Badan Pusat Statistik. 2019. Musi Rawas dalam Angka 2019. Badan Pusat Statistik Kabupaten Musi 
Amin, Andry, Humaidi : Pemetaan Sektor Agribisnis Pangan Unggulan di Kabupaten Musi Rawas.....

Rawas dan Badan Perencana Daerah Kabupaten Musi Rawas. BPS MUsi Rawas.

Abidin, Z. 2018. Identifikasi Komoditas Unggulan Wilayah Dalam Perspektif Pertanian Berkelanjutan Di Sulawesi Tenggara. Mega Aktiva: Jurnal Ekonomi Dan Manajemen. https://doi.org/10.32833/majem.v7i2.71

Adhitama R. 2012. Pengembangan Sektor-Sektor Ekonomi Di Tiap Kecamatan Di Kabupaten Magelang. Economics Development Analysis Journal, 1(2), 1-9. http s://doi.org/10.15294/edaj.vli2.483

Amin, Z. 2016. Rice Consumer Behavior In The Musi Rawas District. International Conference on Agribusiness Development for Human Welfare, 272-278.

Amin, Z. A. 2015. Bargaining Position of Farmers in Tilapia Marketing. 4th AIMI International Conference Proceeding., ISBN: 978-602-7677-80-7. $256-286$.

Arifin, B. 2004. Analisis Ekonomi Pertanian Indonesia. Kompas.

Bachrein S. 2003. Penetapan Komoditas Unggulan Provinsi. BP2TP Working Paper. Bogor. Balai Pengkajian dan Pengembangan Teknologi Pertanian 38 (2): 350-257.

Balai Penelitian Agroklimat dam Hidrologi. 2007. Atlas Sumberdaya Iklim Pertanian Indonesia. Departemen Pertanian Republik Indonesia.

Hardison. 2003. Analisis Strategi Pengembangan Komoditas Unggulan di Kabupaten Siak Provinsi Riau. [Tesis]. IPB.

Haryono, Z. D., \& Kasymir, E. (n.d.). Keunggulan Komparatif dan Kompetitif dalam Produksi Padi di Kabupaten Lampung Tengah Propinsi Lampung Comparative Advantage and Competitive in Paddy Production in Central Lampung Regency, Lampung. 10(3), 185-199.

Hendayana, R. 2003. Aplikasi Metode Location Quotient (LQ) dalam Penentuan Komoditas Unggulan Nasional. Jurnal Informatika Pertanian.

Humaidi, E., Unteawati, B., \& Analianasari, A. 2020. Pemetaan Komoditas Sayur Unggulan Di Provinsi Lampung. Jurnal Agribisnis Indonesia, 8(2), 106-114. https://doi.org/10.29244/jai.2020.8.2.106-114

Kairupan, S. . 2013. Produk Domestik Regional Bruto (PDRB), Inflasi Dan Belanja Daerah Pengaruhnya Terhadap Kesempatan Kerja Di Sulawesi Utara Tahun 2000-2012. Jurnal Riset Ekonomi, Manajemen, Bisnis Dan Akuntansi.

Lumbantoruan, D. M., B. Sartono, and S. D. 2015. Leading Sector Development and Its Implications on the Lending Portfolio and Non-Performing Loan of Small Medium Enterprises. Indonesian Journal of Business and Entrepreneurship, 1(2), 96. https://doi.org/10.17358/ijbe.1.2.96

Makaborang M, Geonadi S, H. P. 2009. Optimalisasi penggunaan lahan berdasarkan kelas kesesuaian lahan untuk pengembangan tanaman perkebunan (Studi Kasus: Kabupaten Sumba Timur). Jurnal Agritech, 29:, $188-197$.

Mufidah, N. L. 2006. Pola Konsumsi Masyarakat Perkotaan: Studi Deskriptif Pemanfaatan Foodcourt oleh Keluarga. Biokultur, 2, 157-178. http://journal.unair.ac.id/filerPDF/05 jurnal nur lailatul----Pola pemanfaatan Foodcourt oleh Keluarga.pdf

Saragih, B. 2001. Suara dari Bogor Membangun Sistem Agribisnis (P. W. M.-P. T. L. G. G. Sarana (ed.)).

Setiawan D. 2006. Peranan Sektor Unggulan Terhadap Pertumbuhan Ekonomi Daerah: Pendekatan InputOutput Multiregional Jawa Timur, Bali dan Nusa Tenggara barat. [Tesis] IPB.

Suntoro, Mujiyo, dan J. S. 2013. Kontribusi Biaya tanaman Pangan terhadap Potensi Global Warming Potensial. Jurnal Ekosain, 5, 57-63. 
Jurnal Penelitian Pertanian Terapan

Suyastiri, N. M. 2008. Diversifikasi Konsumsi Pangan Lokal Berbasis Potensi Lokal dalam Mewujudkan Ketahanan Pangan Rumahtangga Pedesaan Kecamatan Semin Kabupaten Gunung Kidul. Ekonomi Pembanguanan, 13 No 1, 56-60.

Wicaksono, I. A. 2011. Analisis Location Quotient Sektor dan Subsektor Pertanian Pada Kecamatan di Kabupaten Purworejo. Jurnal Ilmu Pertanian, 7(2), 11-18. 